\title{
Genome Structure and Production of Biologically Active In Vitro Transcripts of Cucurbit-Infecting Zucchini green mottle mosaic virus
}

\author{
Ju Yeon Yoon, Byoung Eun Min, Jang Kyung Choi, and Ki Hyun Ryu
}

\begin{abstract}
First, second, and fourth authors: Plant Virus GenBank, Department of Horticultural Science, Division of Environmental and Life Sciences, Seoul Women's University, Seoul 139-774, Korea; and third author: Division of Biological Environment, Kangwon National University, Chunchon 200-701, Korea.
\end{abstract}

Accepted for publication 3 October 2001.

\begin{abstract}
Yoon, J. Y., Min, B. E., Choi, J. K., and Ryu, K. H. 2002. Genome structure and production of biologically active in vitro transcripts of cucurbit-infecting Zucchini green mottle mosaic virus. Phytopathology 92:156-163.

The complete nucleotide sequence of the Zucchini green mottle mosaic virus (ZGMMV), a new member of the genus Tobamovirus, has been determined. The genome of ZGMMV is 6,513 nucleotides long and contains four open reading frames coding for proteins of 131, 189, 28, and $17 \mathrm{kDa}$ from the $5^{\prime}$ to $3^{\prime}$ end, respectively. The $5^{\prime}$ - and $3^{\prime}$-nontranslated regions consist of 59 and 163 residues, respectively. The sequences of the viral proteins exhibit high identity to the proteins of the members of the genus Tobamovirus and are distinct from other viruses within the subgroup of cucurbit-infecting tobamoviruses. Results from

fruit mottle mosaic virus and is less similar to Cucumber green mottle mosaic virus. Full-length cDNA of ZGMMV was directly amplified by reverse-transcription polymerase chain reaction (RT-PCR) using the $5^{\prime}$ end primer containing a T7 RNA promoter sequence and $3^{\prime}$-end primer. Capped in vitro transcript from the RT-PCR products was infectious on zucchini squash, cucumber, and Nicotiana benthamiana plants. This cellfree system to produce infectious transcripts from uncloned cDNA copies is useful for quick assessment of infectivity of transcripts from plant RNA viruses prior to cloning. Synthesized capped transcript from a fulllength cDNA clone of the virus was highly infectious. Progeny virus derived from infectious transcripts had the same biological and biochemical properties as wild-type virus. To our knowledge, this is the first report of a biologically active transcript from a cucurbit-infecting tobamovirus.
\end{abstract} phylogenetic trees of the coding regions demonstrated that ZGMMV is a very close relative of Kyuri green mottle mosaic virus and Cucumber
Additional keywords: infectious clone, phylogeny, taxonomy.
The genus Tobamovirus is one of the biologically and molecularly best-characterized groups with many species and strains varying widely in host range and in its interaction with host plants $(1,10,14,16,21-23,29,30,33,40)$. Tobamoviruses constitute a group of plant viruses with single positive-sense RNA molecules as genomes and rod-shaped virions consisting of viral RNA surrounded by a single coat protein $(\mathrm{CP})$. The genomes are capped at the $5^{\prime}$ end and have a tRNA-like structure at the $3^{\prime}$ end $(21,43)$. Tobamoviral RNAs encode four polypeptides. Two large polypeptides, $130-$ and $180-\mathrm{kDa}$ proteins, function in viral RNA replication and are translated from the same $5^{\prime}$-proximal start codon. The $30-\mathrm{kDa}$ movement protein (MP) required for cell-to-cell movement and the $17-\mathrm{kDa} \mathrm{CP}$ are translated from $3^{\prime}$-coterminated subgenomic mRNAs derived from the $3^{\prime}$ portions of the tobamoviral RNAs. To date, infectious cDNA clones and in vitro transcripts have been obtained for tobamoviruses including Tobacco mosaic virus (TMV), Tomato mosaic virus (ToMV), Obuda pepper virus (ObPV), Turnip vein-clearing virus (TVCV), and Odontoglossum ringspot virus (ORSV) $(6,9,17-19,24,28,39,41,42)$.

Cucurbitaceous vegetable crops including cucumber, melon, watermelon, zucchini squash, and cantaloupe can be destroyed when infected by several viruses such as Cucumber green mottle mosaic virus (CGMMV), Cucumber mosaic virus, Kyuri green mottle mosaic virus (KGMMV), Squash mosaic virus, and Zucchini yellow mosaic virus $(7,12,26,37)$.

Corresponding author: K. H. Ryu; E-mail address: ryu @swu.ac.kr

Publication no. P-2001-1130-01R

(C) 2002 The American Phytopathological Society
During recent 3-year surveys of viral diseases conducted in the southern area (Chonju in Chonpook Province) of the Republic of Korea from 1999 until 2001, zucchini squash plants grown in commercial farms were observed to exhibit green mottle and severe mosaic symptoms. A virus with molecular characteristics similar to those in the genus Tobamovirus was originally isolated from the zucchini squash plants showing mottle and severe mosaic and abnormal fruits symptoms in Korea. Recently, the virus was partially characterized and determined to be a new member of the genus Tobamovirus based on host range and nucleotide and deduced amino acid sequence of the CP (29). The species name was Zucchini green mottle mosaic virus (ZGMMV). Thereafter, a new cucurbit-infecting tobamovirus called Cucumber fruit mottle mosaic virus (CFMMV) was isolated from cucumber plant in Israel, and its biological, serological, and molecular characterization was reported (3). Antignus et al. (3) divided cucurbit-infecting tobamoviruses into two subgroups based on comparisons of sequences and phylogenetic analysis: subgroup I comprising the strains and isolates of CGMMV and subgroup II including CFMVIV, KGMMV (formerly referred to as CGMMV-C), and Yodo strain of KGMMV (KGMMV-Y; formerly referred to as CGMMV-Y).

In this study, we have completed the determination of nucleotide sequence and genome organization for ZGMMV. Phylogenetic analysis as well as sequence alignments of the coding and noncoding regions of ZGMMV were compared with those of other members of the genus Tobamovirus including various cucurbit-infecting tobamoviruses in order to clarify the taxonomic status of ZGMMV and of other viruses within this genus. To our knowledge, this is the first information on the biological, serological, and molecular characterization of this new Tobamovirus. To 
obtain a system for studying functions of the virus genome and molecular plant-pathogen interactions and for developing a viral vector, we have constructed a full-length cDNA clone from which infectious transcripts can be synthesized. We describe the production of biologically active in vitro transcripts of ZGMMV.

\section{MATERIALS AND METHODS}

Virus source, plants and host range analysis. A zucchini strain of ZGMMV (ZGMMV-Zu) was isolated from zucchini squash (Cucurbita pepo L. var. zucchini) and used in this study. KGMMV-Cl, CGMMV-W, and TMV-U1 were obtained from the Plant Virus GenBank (Seoul Women's University, Seoul, Korea), and were maintained on zucchini squash, cucumber, and tobacco (cv. Samsun), respectively, by mechanical inoculation (29). Zucchini squash (cv. Black Beauty), cucumber (Cucumis sativus L. cv. Baekdadaki), and Nicotiana benthamiana were grown and assayed for ZGMMV infection. ZGMMV was propagated in zucchini squash, and virions were purified from infected leaves as described previously (5). Viral genomic RNAs were isolated from purified virion preparations by the sodium dodecyl sulfate (SDS)/ proteinase K-phenol extraction method (30). To determine the host range of ZGMMV, crude sap from leaf samples of the virusinfected zucchini squash were mechanically inoculated to 21 plant species representing six families (Table 1) predusted with Carborundum (320 grit, Fisher Scientific, Fair Lawn, NJ). These plants were maintained in a glasshouse and observed for symptom development.

Western and northern blot analyses. Antibodies against ZGMMV, KGMMV, CGMMV-W, and TMV-Ul were produced in New Zealand white rabbits (Han Rim Experimental Animal Farm, Seoul, Korea) and used for double-antibody sandwich enzymelinked immunosorbent assay (DAS-ELISA) and western blot analysis. ZGMMV CP extracted from infected plant tissue was separated on a $12 \%$ SDS-polyacrylamide gel and transferred onto a nitrocellulose (NC) membrane by electro-blotting with a transfer electroblot unit (Bio-Rad Laboratories, Hercules, CA). Membrane was washed three times with TBST (20 mM Tris [pH 7.5], $150 \mathrm{mM}$ $\mathrm{NaCl}$, and $0.1 \%$ Tween 20) buffer and blocked for $4 \mathrm{~h}$ at $25^{\circ} \mathrm{C}$ in the same solution with $5 \%$ nonfat milk $(29,32)$. Membrane was probed with rabbit antibody (1:1,500 dilutions; immunoglobulin $\mathrm{G}$ [IgG] fraction; $1 \mathrm{mg} / \mathrm{ml}$ ) against ZGMMV CP (29). Membrane was washed three times in TBST buffer and incubated with an alkaline phosphatase (AP)-conjugated secondary antibody $(1: 7,500$ dilution; Promega Corp., Madison, WI). Membrane was washed three times with TBST buffer and rinsed once in AP-substrate buffer (0.1 M Tris [pH 9.5], $100 \mathrm{mM} \mathrm{NaCl}$, and $50 \mathrm{mM} \mathrm{MgCl}_{2}$ ). To visualize antibody-specific proteins, membrane was exposed to AP-substrate solution (Western Blue Stabilized Substrate Solution; Promega).

Viral RNAs were separated on a $1.4 \%$ formaldehyde denaturing agarose gel (32), transferred onto an NC membrane, and hybridized with ${ }^{32} \mathrm{P}$-labeled probes produced by transcription from ZGMMV CP gene clone pZG040 using SP6 RNA polymerase (Promega) for northern blot analysis (32). Molecular weight of transcript was determined by comparing its mobility with those of the RNA size standards (0.24- to 9.4-kb RNA ladder; Gibco BRL, Rockville, MD).

DAS-ELISA analysis. Serological relationships between ZGMMV and CGMMV and KGMMV and TMV were compared by DAS-ELISA according to the procedure described by Clark and Adams (8). Polysorp immunoplates (96 wells; Nunc, Roskilde, Denmark) were coated with $1 \mu \mathrm{g} / \mathrm{ml}$ of purified antibodies (IgG) from polyclonal rabbit antisera against each virus. Plates were incubated with $200 \mu \mathrm{l}$ of purified virus $(0.1 \mathrm{mg} / \mathrm{ml})$ and incubated for $4 \mathrm{~h}$ at $37^{\circ} \mathrm{C}$ before $200 \mu \mathrm{l}$ of AP-labeled IgGs $(1: 1,000$ dilution) against each virus was applied. After incubation for $2 \mathrm{~h}$ at $37^{\circ} \mathrm{C}, 200 \mu \mathrm{l}$ of freshly prepared $p$-nitrophenyl phosphate
( $1 \mathrm{mg} / \mathrm{ml}$ ) in $0.1 \mathrm{M}$ diethylamine substrate buffer ( $\mathrm{pH} 9.8$ ) was added to each well, and optical density was measured at $405 \mathrm{~nm}$ with a microplate reader (Model EL340; Bio-Tek Instruments, Inc., Winooski, VT). ELISA plates were washed three times with phosphate-buffered saline ( $0.1 \%$ Tween 20$)$ between each step (8).

Reverse transcription and polymerase chain reaction. Reverse transcription and polymerase chain reaction (RT-PCR) was performed for ZGMMV infection in tested hosts. Total nucleic acids from ZGMMV-infected tissue were reverse-transcribed using Moloney murine leukemia virus reverse transcriptase (Gibco BRL; with downstream primer ZG3CP (5'-CAAGACGAGGTAGACGAAC-3', 6331-6349). The cDNA was then amplified by PCR using Taq DNA polymerase (Promega Corp.) and primers ZG3CP and ZG5CP (5'-ATGCCTTACTCTACCAGCG-3', 58475865), which amplify a 486-bp fragment corresponding to the entire region of $\mathrm{CP}$ gene. Cycling conditions were as follows; 30 cycles at $94^{\circ} \mathrm{C}$ for $1 \mathrm{~min}, 52^{\circ} \mathrm{C}$ for $1 \mathrm{~min}$, and $72^{\circ} \mathrm{C}$ for $1 \mathrm{~min}$ preceded by an initial incubation at $94^{\circ} \mathrm{C}$ for $2 \mathrm{~min}$, and a final extension at $72^{\circ} \mathrm{C}$ for $3 \mathrm{~min}$.

cDNA synthesis, cloning, and nucleotide sequencing. The $3^{\prime}$ termini of the purified genomic viral RNAs were polyadenylated with Escherichia coli poly (A) polymerase (Gibco BRL). cDNA was synthesized from $10 \mu \mathrm{g}$ of the polyadenylated viral genomic RNA with a plasmid choice cDNA synthesis and cloning kit (Gibco BRL). Double-stranded cDNA molecules were cloned into NotI/SalI sites of pSPORT1 vector (Gibco BRL). The recombinant plasmids were transformed into E. coli (strain JM109). Overlapping deletion clones were generated by unidirectional deletion with exonuclease and S1 nuclease (Erase-A-Base kit; Promega). Clones were sequenced in both directions by the dideoxynucleotide chain termination method with an automated DNA sequencer (Model 377; Applied Biosystems, Inc., Foster City, CA). The 5'terminal sequences of the ZGMMV were determined by RNAprimer extension analysis of genomic RNA of the virus. One picomol of primer ZG150 (5'-GAGTTTACGATGAGGCGGTGAA-3') end-labeled with $\left[\gamma^{32} \mathrm{P}\right]$ ATP by T4 polynucleotide kinase (United States Biochemical Corp., Cleveland) was anneal-

TABLE 1. Experimental host range and symptoms of Zucchini green mottle mosaic virus (ZGMMV) isolated from zucchini squash

\begin{tabular}{|c|c|c|}
\hline Family & Species & Symptoms ${ }^{\mathrm{a}}$ \\
\hline Amaranthaceae & Gomphrena globosa & CS/M,Mal \\
\hline Brassicaceae & Brassica campestris sp. pekinensis & $-1-$ \\
\hline \multirow[t]{2}{*}{ Chenopodiaceae } & Chenopodium amaranticolor & $-1-$ \\
\hline & Chenopodium quinoa & $-1-$ \\
\hline \multirow[t]{11}{*}{ Cucurbitaceae } & Citrullus vulgaris & SL/M,Mal \\
\hline & Cucumis melo & SL/M,Mal \\
\hline & Cucumis sativus 'Baekdadaki' & SL/CS,M,Mo,Mal \\
\hline & Cucurbita maxima & SL/M,Mo \\
\hline & Cucurbita moschata & SL/M,Mo \\
\hline & Cucurbita pepo 'Black Beauty' & SL/CS,M,Mo,Mal \\
\hline & Cucurbita pepo 'Choigobong' & SL/CS,M,Mo,Mal \\
\hline & Cucurbita pepo 'Cocozelle' & SL/CS,M,Mo \\
\hline & Cucurbita pepo 'Gold Rush' & SL/CS,M,Mo,Mal \\
\hline & Cucurbita pepo 'Taeyang' & SL/CS,M,Mo \\
\hline & Lagenaria siceraria & SL/M,Mo \\
\hline \multirow[t]{3}{*}{ Leguminosae } & Glycine $\max$ & $-1-$ \\
\hline & Phaseolus vulgaris & $-1-$ \\
\hline & Vigna unguiculata & $-1-$ \\
\hline \multirow[t]{7}{*}{ Solanaceae } & Capsicum annuum 'Golden Tower' & $-1-$ \\
\hline & Datura stramonium & NS/- \\
\hline & Lycopersicon esculentum & $-1-$ \\
\hline & Nicotiana benthamiana & SL/M,Mo,Mal \\
\hline & Nicotiana glutinosa & $-1-$ \\
\hline & Nicotiana tabacum 'Samsun' & $-1-$ \\
\hline & Nicotiana tabacum 'Xanthi-nc' & $-1-$ \\
\hline
\end{tabular}

a Symptoms on inoculated leaves and upper uninoculated leaves are to the left and right of the slash, respectively. Abbreviations for symptoms: -, no infection; CS, chlorotic spots; M, mosaic; Mal, malformation; Mo, mottle; NS, necrotic spots; and SL, symptomless latent infection. 
ed to $10 \mu \mathrm{g}$ of the genomic RNA. Primer extension reactions using Avian myeloblastosis virus reverse transcriptase (United States Biochemical Corp.) were incubated at $42^{\circ} \mathrm{C}$ for $60 \mathrm{~min}$, denatured, and resolved on $6 \%$ polyacrylamide sequencing gels. The $5^{\prime}$-end region was also cloned using PCR by the rapid amplification of the cDNA ends (RACE) (Smart RACE cDNA; Clontech Laboratories Inc., Palo Alto, CA).

Sequence comparison and phylogenetic analysis. Nucleotide and amino acid sequence alignments and phylogenetic analysis of the coding and noncoding regions of ZGMMV and other members of the genus Tobamovirus were performed to clarify the taxonomic status of ZGMMV and of other viruses within the genus. Nucleotide and amino acid sequences were analyzed with the DNAMAN package (version 5.1; Lynnon Biosoft, Quebec, Canada). Pairwise sequence comparisons and alignments were done with a multiple sequence editor program in the DNAMAN package, with a gap open penalty of 10 and a gap extension penalty of 5 (nucleotide analysis) or a gap open penalty of 10 and a gap extension penalty of 0.2 (amino acid analysis). Sequences of members of the genus Tobamovirus for comparisons were obtained from GenBank under the following accession numbers: CFMMV, AF321057 (3); CGMMV-SH, D12505 (38); Frangipani mosaic virus (FrMV), AF165884; KGMMV-Y, ABO15145 (37); ObPV, L11665 (28); ORSV, X82130 (30); Pepper mild mottle virus (PMMoV-S), M81413 (2); Ribgrass mosaic virus (RMV), AF187045 and AF185272; Sunn-hemp mosaic virus (SHMV),
U47034 and J02413 (35); TMV, V01408 (15); Tobacco mild green mosaic virus (TMGMV), M34077 (36); ToMV, X02144 (27); TVCV, U03387 (20); and Youcai mosaic virus (YoMV; formerly referred to as Oilseed rape mosaic virus), U30944 (1).

Phylogenetic analysis was performed to determine the relationship of ZGMMV with other members of the genus Tobamovirus using the neighbor-joining algorithm in the DNAMAN package according to Saitou and Nei (31). The data set was subjected to 1,000 bootstrap replicates.

Construction of a full-length cDNA clone of ZGMMV. Fulllength cDNA was amplified with primers specific to the $5^{\prime}$ end and $3^{\prime}$ end of the virus by RT-PCR as depicted in Figure 1A. The $3^{\prime}$-end primer (ZG3SPH) contains a SphI site for cloning and a $5^{\prime}$ end primer ZGET7 contains an EcoRI recognition and T7 RNA promoter sequence for cloning and in vitro transcription (Fig. 1A). The primers were synthesized commercially (Bioneer Corp., Taejon, Korea). The first-strand cDNA was synthesized by RT with SuperScript II reverse transcriptase (Gibco BRL). PCR was performed with first-strand cDNA from $0.1 \mu \mathrm{g}$ of viral RNAs and Expand long template DNA polymerase (Roche Diagnostics $\mathrm{GmbH}$, Mannheim, Germany) in a thermalcycler (iCycler; BioRad Laboratories). PCR was performed for $2 \mathrm{~min}$ at $94^{\circ} \mathrm{C}$ followed by five cycles of $20 \mathrm{~s}$ at $94^{\circ} \mathrm{C}, 30 \mathrm{~s}$ at $55^{\circ} \mathrm{C}$, and $7 \mathrm{~min}$ at $68^{\circ} \mathrm{C}, 10$ cycles of $20 \mathrm{~s}$ at $94^{\circ} \mathrm{C}, 30 \mathrm{~s}$ at $57^{\circ} \mathrm{C}$, and $8 \mathrm{~min}$ at $68^{\circ} \mathrm{C}$, and 10 cycles of $20 \mathrm{~s}$ at $94^{\circ} \mathrm{C}, 30 \mathrm{~s}$ at $59^{\circ} \mathrm{C}$, and $9 \mathrm{~min}$ at $68^{\circ} \mathrm{C}$. The reaction was terminated by a 10 -min elongation period at

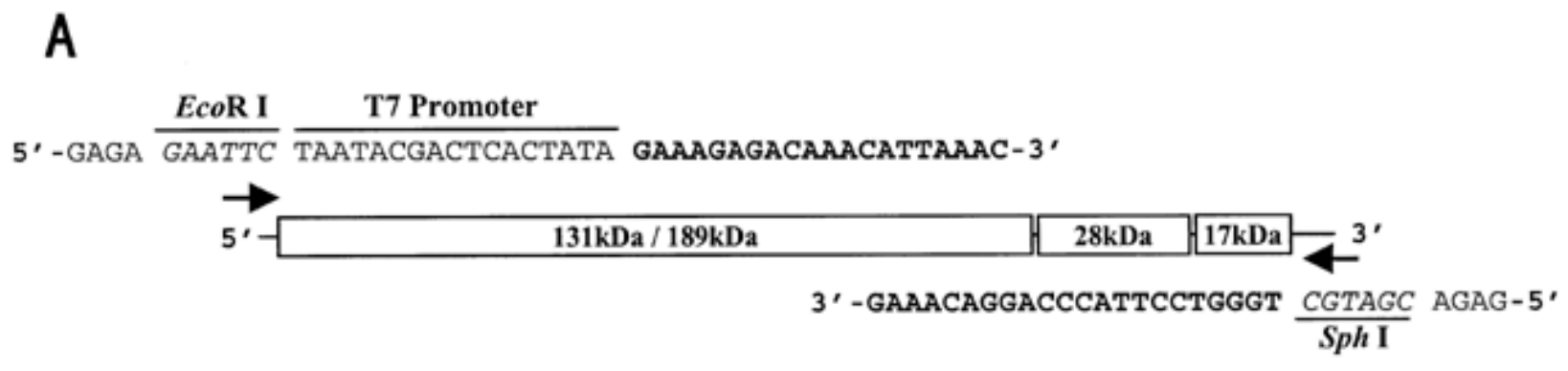

pZGT7ES

$\mathrm{T} 7$ promoter
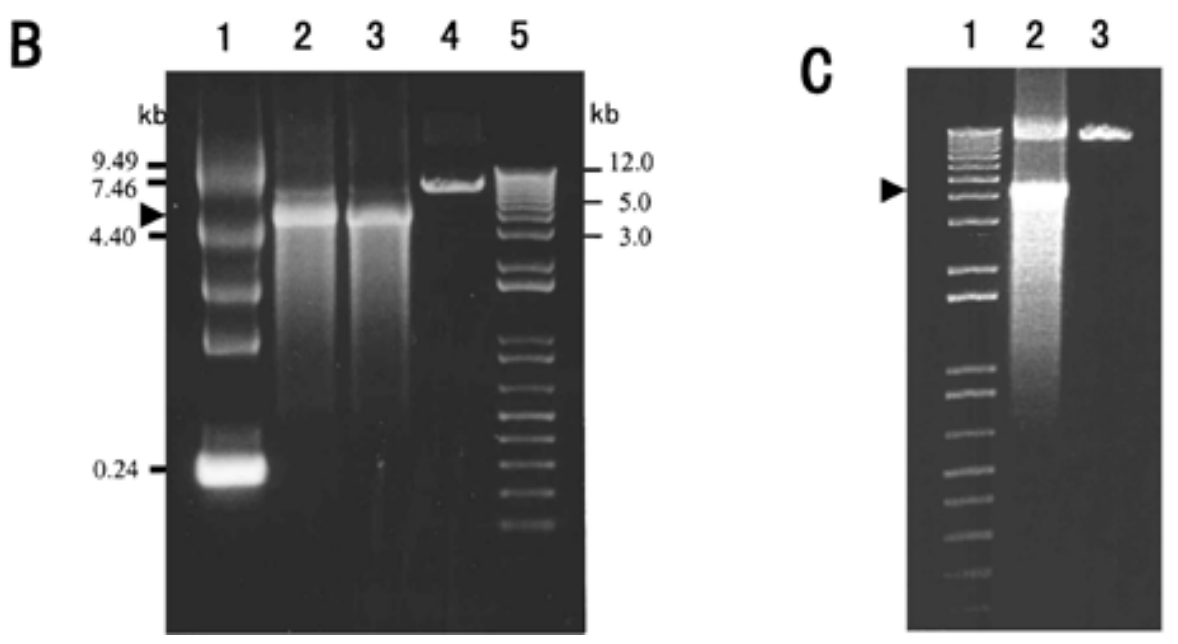

Fig. 1. Construction of a full-length cDNA clone (pZGT7ES) of Zucchini green mottle mosaic virus (ZGMMV). A, The 5'-end (containing T7 RNA promoter sequences) and $3^{\prime}$-end primers used for amplification of full-length cDNA are detailed on the corresponding region. B, Electrophoretic pattern of reverse transcription and polymerase chain reaction (RT-PCR) product and in vitro transcripts RNA from the full-length RT-PCR product for ZGMMV. RNA markers (0.24- to 9.4-kb RNA ladder; Gibco BRL, lane 1), transcripts RNAs transcribed from SphI-uncut (lane 2), transcripts RNAs transcribed from SphI-cut (lane 3), full-length RT-PCR product (lane 4), 1 kb plus DNA ladder (Gibco BRL). C, Electrophoretic pattern of in vitro transcripts RNA transcribed from SphI-cut linearized full-length cDNA clone pZGT7ES. Lane 1, 1-kb plus DNA ladder; lane 2, transcripts RNAs transcribed from the clone; and lane 3, SphI-linearized pZGT7ES. Arrowheads indicate the $6.5 \mathrm{~kb}$ long transcripts RNA for ZGMMV. 
$68^{\circ} \mathrm{C}$. An aliquot of the final products was analyzed by agarose gel electrophoresis. Amplified RT-PCR products were used directly for in vitro transcription reaction or digested with $E c o \mathrm{RI} / S p h \mathrm{I}$ and cloned into EcoRI/SphI-digested pUC18.

In vitro transcription and infectivity assay. RT-PCR products of full-length cDNA of ZGMMV were directly used or digested with $S p h \mathrm{I}$ and used as template DNA for in vitro transcription. A full-length cDNA clone of the ZGMMV (pZGT7ES) was also used as template for transcription reactions following plasmid linearization with $S p h \mathrm{I}$. In vitro transcription was performed in the presence or absence of cap analog $\left(\mathrm{m}^{7} \mathrm{G}\left[5^{\prime}\right] \mathrm{ppp}\left[5^{\prime}\right] \mathrm{G}\right.$; New England Biolabs, Inc., Beverly, MA) using T7 RNA polymerase (Promega). The quality and quantity of transcripts was assessed by loading onto a $1 \%$ agarose gel. Each plant was inoculated with 2.0 to $3.0 \mu \mathrm{g}$ of transcripts onto Carborundum-dusted cotyledons of zucchini squash and cucumber plants. $N$. benthamiana plants at the four-to-five leaf stage were also inoculated with the in vitro transcripts. Infectivity was verified by western and northern blot analyses and by RT-PCR.

\section{RESULTS AND DISCUSSION}

Host range of ZGMMV. ZGMMV was originally detected and isolated from naturally grown zucchini squash plants exhibiting green mottle and mosaic symptoms on leaves and abnormal malformed fruits displaying an irregular mild green mosaic. Virus was detected in these plants and confirmed by RT-PCR and ELISA analysis (data not shown). The symptoms were masked or showed mild mosaic in leaves that developed when plants were grown in a glasshouse with high humidity and high temperatures. ZGMMV is found naturally only on zucchini squash, where it causes severe mosaic and mottle in leaf and fruit parts. ZGMMV was mechanically transmitted to 10 plant species listed in Table 1 . The virus produced necrotic spots in inoculated leaves in Datura stramonium, which can be used as a local lesion assay host for the virus. The virus induced systemic symptoms in Gomphrena globosa, $N$. benthamiana, and all seven cucurbitaceous plant species analyzed. There is no report of KGMMV or CFMMV in Korea, which have been reported in Japan and Israel, respectively $(3,37)$. However, CGMMV is widespread in some cucurbitaceous plants in fields in Korea (7). ZGMMV displayed a host range similar to those of KGMMV, CGMMV, and CFMMV $(3,37,38)$. These four cucurbitinfecting tobamoviruses have overlapping host ranges but cause different host reactions in some species such as G. globosa, Chenopodium amaranticolor, D. stramonium, and zucchini squash. ZGMMV does not infect Chenopodium amaranticolor but produces systemic symptoms in G. globosa and zucchini squash, and induced local lesions in D. stramonium. However, CGMMV and CFMMV produce local lesions in Chenopodium amaranticolor but cannot infect G. globosa (3). ZGMMV can induce severe fruit symptoms in zucchini squash but CGMMV does not infect or has a symptomless reaction in this plant.

TABLE 2. Serological relationships of Zucchini green mottle mosaic virus (ZGMMV), Kyuri green mottle mosaic virus (KGMMV), Cucumber green mottle mosaic virus (CGMMV), and Tobacco mosaic virus (TMV) determined by double-antibody sandwich enzyme-linked immunosorbent assay (DAS-ELISA)

\begin{tabular}{lcccc}
\hline & \multicolumn{4}{c}{ Polyclonal antiserum against ${ }^{\mathrm{a}}$} \\
\cline { 2 - 5 } Antigen & ZGMMV & KGMMV & CGMMV & TMV \\
\hline ZGMMV & +++++ & + & - & - \\
KGMMV & + & ++++ & - & - \\
CGMMV & - & - & ++++ & - \\
TMV & - & - & - & ++++ \\
\hline
\end{tabular}

${ }^{a}$ Serological reactivity measured by DAS-ELISA as the absorbance (A) at $405 \mathrm{~nm}:-, \mathrm{A}<0.05 ;+, 0.05<\mathrm{A}<0.1 ;++, 0.1<\mathrm{A}<0.5 ;+++, 0.5<\mathrm{A}<$ $1.0 ;++++, 1.0<\mathrm{A}<1.5 ;$ and,$+++++ \mathrm{A}>1.5$.
Symptoms induced by ZGMMV in all cucurbitaceous plants were more severe than those induced by CGMMV or KGMMV (data not shown). Therefore, cucurbit-infecting tobamoviruses can be distinguished biologically by the differing responses they elicit in Chenopodium amaranticolor, D. stramonium, and G. globosa.

Serological relationships. ZGMMV, KGMMV, CGMMV, and TMV were compared serologically by DAS-ELISA using polyclonal antisera against each virus (Table 2). The viruses reacted strongly with their homologous antisera, and weakly or not at all with heterologous antisera, demonstrating that the reactivity among the three viruses were not identical. ZGMMV reacted very weakly with the antiserum against KGMMV, but not with the antisera against CGMMV or TMV. In agarose gel double-diffusion (GDD) tests with the viruses and the antisera combinations, positive precipitin lines developed only in homologous antigenantibody combinations (data not shown). DAS-ELISA and GDD analyses confirmed the lack of serological cross-reaction between ZGMMV and CGMMV and TMV. This suggests that ZGMMV appears distantly related to KGMMV, but not with CGMMV and TMV by serological analyses (Table 2 ).

Complete nucleotide sequence and genome organization of ZGNIMV. A total of 29 recombinant plasmids with cDNA inserts ranging from 600 to $1,800 \mathrm{bp}$ were identified that contained overlapping cDNA fragments of ZGMMV genome. These were used to determine the sequence of the viral genome. The genome of the virus was 6,513 nucleotides long and contained four open reading frames (ORFs) coding for proteins of $M_{\mathrm{r}} 131 \mathrm{kDa}(1,166$ amino acids [aa]), $189 \mathrm{kDa}(1,669 \mathrm{aa})$ as a readthrough product of the 131-kDa protein, $28 \mathrm{kDa}(261 \mathrm{aa})$, and $17 \mathrm{kDa}$ (161 aa) from the $5^{\prime}$ to $3^{\prime}$ end, respectively. ZGMMV genome and that of KGMMV-Y (37) and CFMMV (3) were slightly longer than that of other tobamoviruses identified in which the extra nucleotide sequences are located in the $5^{\prime}$ end (157 to 173 aa) and central portion (638 to 678 aa) of the $131-\mathrm{kDa}$ protein. Comparison of the amino acid sequences of the four proteins of ZGMMV with the corresponding sequences of other members of the genus Tobamovirus revealed 92.2 to $23.8 \%$ sequence identity (Table 3 ). The complete nucleotide sequence for the virus reported in this study appears as GenBank Accession No. AJ295949. Tobamoviruses can be divided into three subgroups that can be distinguished from one

TABLE 3. Comparison of percentage of similarity of amino acid (aa) and nucleotide (nt) sequences between Zucchini green mottle mosaic virus (ZGMMV) and other members of the genus Tobamovirus ${ }^{\mathrm{a}}$

\begin{tabular}{|c|c|c|c|c|c|c|c|c|}
\hline \multirow[b]{2}{*}{ Virus } & \multicolumn{2}{|c|}{$131 \mathrm{kDa}$} & \multicolumn{2}{|c|}{$189 \mathrm{kDa}$} & \multicolumn{2}{|c|}{$28 \mathrm{kDa}$} & \multicolumn{2}{|c|}{$17 \mathrm{kDa}$} \\
\hline & aa & nt & aa & nt & aa & nt & aa & nt \\
\hline CGMMV-SH & 60.9 & 59.5 & 75.7 & 69.4 & 59.8 & 59.6 & 45.3 & 56.4 \\
\hline KGMMV-Y & 92.2 & 81.4 & 91.7 & 82.3 & 87.3 & 81.5 & 76.4 & 80.4 \\
\hline CFMMV & 80.7 & 71.3 & 85.1 & 77.2 & 77.8 & 69.5 & 77.6 & 76.9 \\
\hline TMV & 42.5 & 49.0 & 57.6 & 57.8 & 31.5 & 42.2 & 36.1 & 47.6 \\
\hline ToMV & 42.2 & 48.7 & 57.8 & 57.2 & 31.6 & 41.3 & 32.3 & 45.1 \\
\hline TMGMV & 41.6 & 48.1 & 54.6 & 56.5 & 31.3 & 43.0 & 35.4 & 46.9 \\
\hline YoMV & 42.8 & 49.8 & 56.8 & 56.4 & 31.7 & 39.2 & 31.4 & 42.9 \\
\hline ORSV & 39.7 & 47.5 & 55.5 & 58.6 & 31.5 & 40.9 & 35.9 & 43.7 \\
\hline PMMoV-S & 40.8 & 47.5 & 56.9 & 57.9 & 32.0 & 42.2 & 35.3 & 45.8 \\
\hline SHMV & 41.7 & 47.2 & 51.5 & 55.0 & 23.8 & 37.8 & 44.1 & 52.1 \\
\hline ObPV & 42.1 & 48.7 & 54.8 & 57.9 & 32.4 & 43.2 & 32.7 & 42.9 \\
\hline TVCV & 43.5 & 49.1 & 56.8 & 57.0 & 30.1 & 38.2 & 33.3 & 42.9 \\
\hline RMV & - & - & - & - & 31.3 & 39.0 & 30.8 & 42.4 \\
\hline FrMV & - & - & - & - & 34.9 & 46.6 & - & - \\
\hline
\end{tabular}

${ }^{\text {a }}$ Cucumber green mottle mosaic virus (CGMMV), Kyuri green mottle mosaic virus (KGMMV), Cucumber fruit mottle mosaic virus (CFMMV), Tobacco mosaic virus (TMV), Tomato mosaic virus (ToMV), Tobacco mild green mosaic virus (TMGMV), Youcai mosaic virus (YoMV), Odontoglossum ringspot virus (ORSV), Pepper mild mottle virus (PMMoV-S), Sunn-hemp mosaic virus (SHMV), Obuda pepper virus (ObPV), Turnip vein-clearing virus (TVCV), Ribgrass mosaic virus (RMV), and Frangipani mosaic virus (FrMV). The 189-kDa readthrough region was analyzed; - indicates not analyzed. 
another based on nucleotide and amino acid similarities, phylogenetic clustering, position of the origin of virion assembly, and organization of the gene junction $(1,13,14,21,29,33)$. There is no overlapping junction between the ORFs of ZGMMV and thus this genome organization mimics that of PMMoV, KGMMV, and CFMMV $(2,3,37)$. A conserved motif ' $\mathrm{F}-\mathrm{E}-\times 6-\mathrm{W}^{\prime}$ is present near the C-termini of the CP of ZGMMV and all of the other tobamoviruses sequenced so far. This motif is also present within the CPs of other viruses that have rod-shaped particles, such as Soil-borne wheat mosaic virus, Indian peanut clump virus, and Tobacco rattle virus $(4,25,34)$. The MP and $\mathrm{CP}$ genes are the most hetero- geneous regions among the tobamoviruses sequenced to date (13, $14,21)$. The CP was the least conserved protein among those encoded by four cucurbit-infecting tobamoviruses (ZGMMV, KGMMV, CGMMV, and CFMMV) when pairwise comparisons were made between the proteins of these viruses (data not shown). This may represent variation in the host reaction and other pathogenicity and serological relationships. It is interesting to note that the 131- and 189-kDa replicases of these four tobamoviruses are the most conserved among the encoded proteins in amino acid level, perhaps because it is involved in a basic process of virus multiplication.

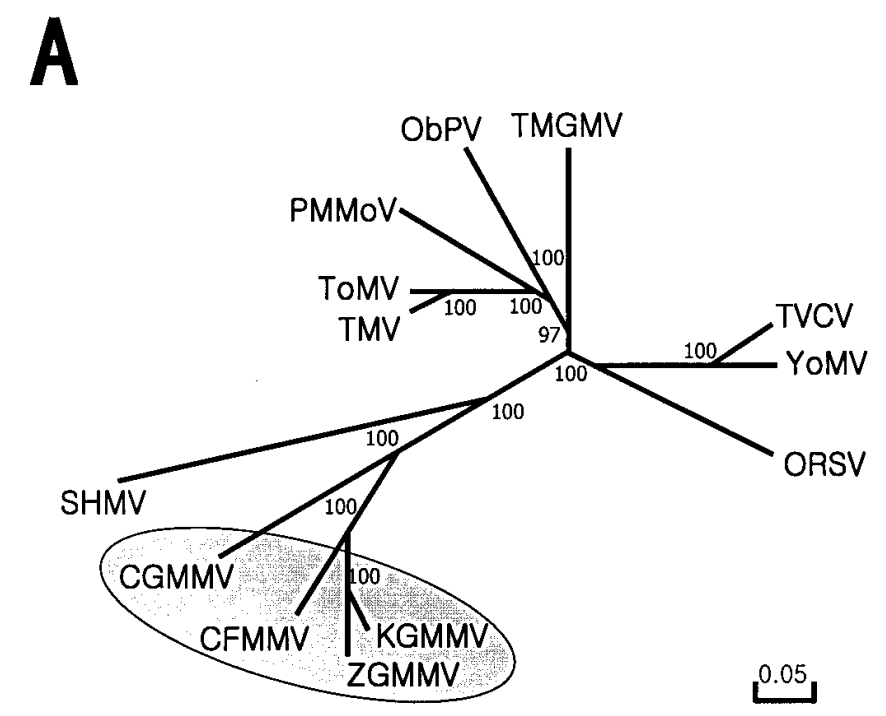

B
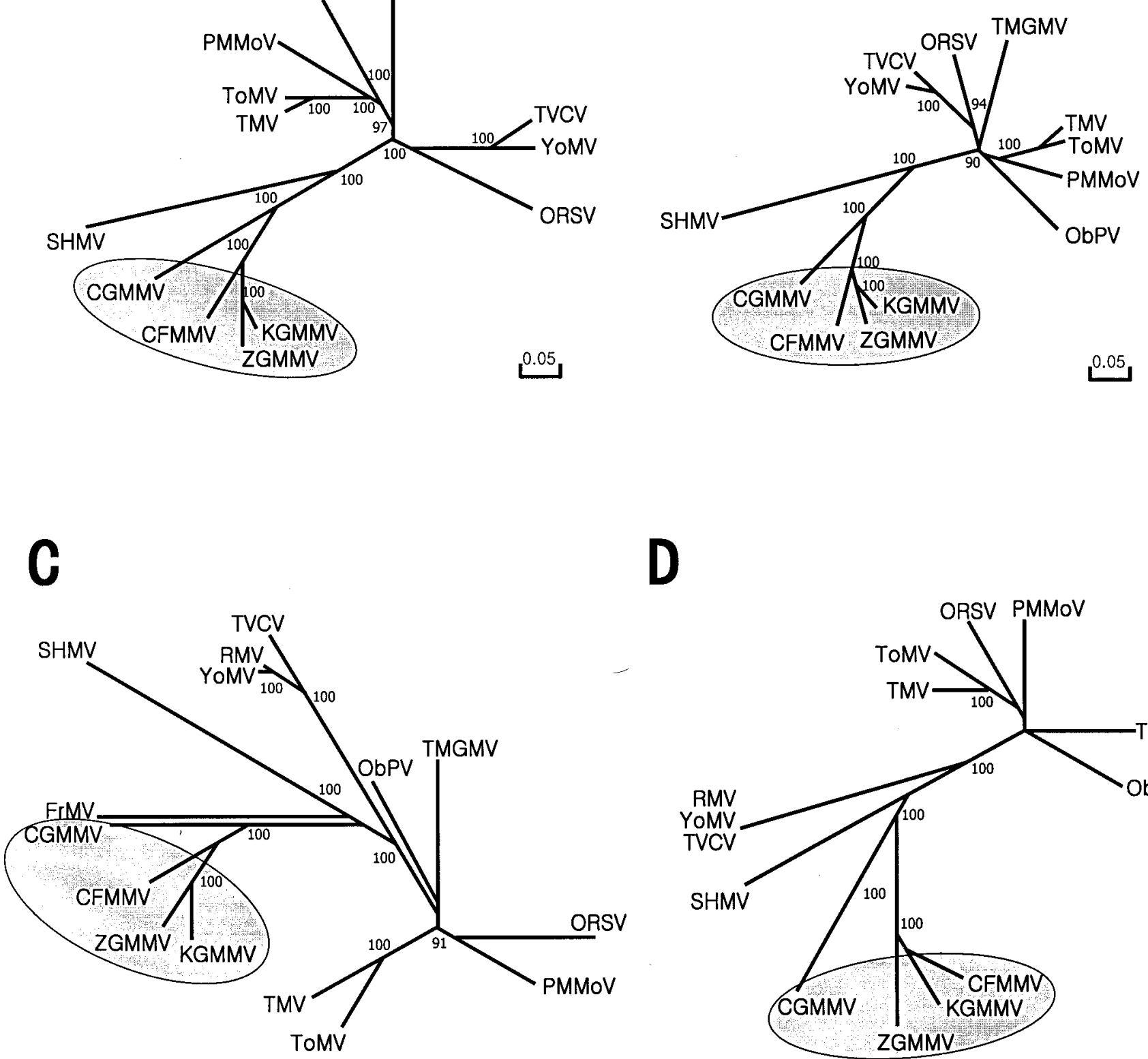

D

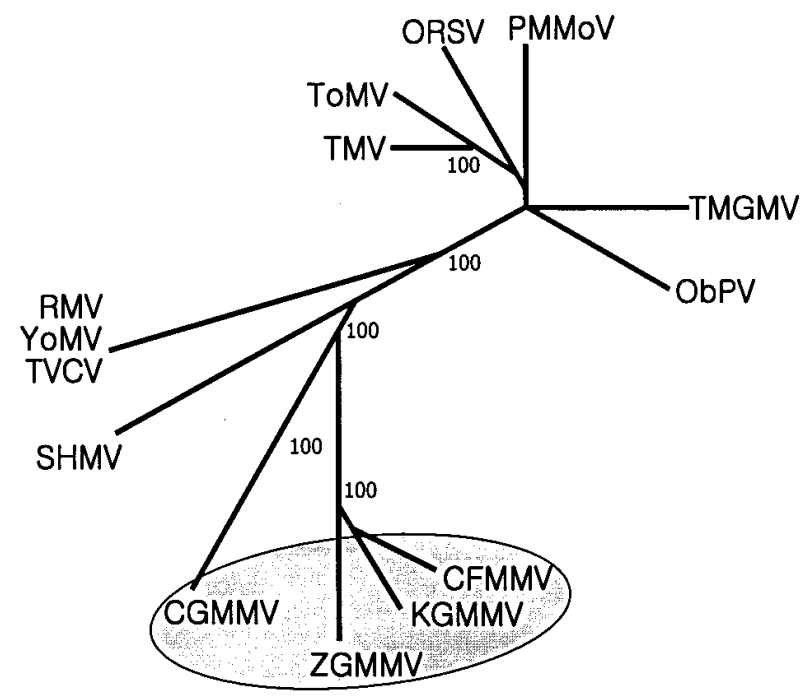

0.05

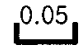

Fig. 2. Phylogenetic relationships of Zucchini green mottle mosaic virus (ZGMMV) and members of the genus Tobamovirus based on the A, 131-kDa protein, B, 189-kDa readthrough portion, C, 28-kDa movement protein, and D, 17-kDa coat protein. Multiple sequence alignments were generated using the DNAMAN package (Lynnon Biosoft, Quebec, Canada), and phylogenetic trees were constructed by the neighbor-joining algorithm based on calculations from pairwise amino acid sequence distances for protein analyses derived from the multiple alignment format. The horizontal branch lengths are proportional to the genetic distance, and numbers at each branch point indicate bootstrap values. Branch values not shown are greater than $90 \%$. The data set was subjected to 1,000 bootstrap replicates. 
Phylogenetic analysis. Phylogenetic analyses were conducted with ZGMMV and members of the genus Tobamovirus based on the coding regions at the amino acid level. The phylogenetic trees reflecting the evolutionary positions of the members of the genus Tobamovirus could be constructed (Fig. 2). Results from the phylogenetic trees of the coding regions demonstrated that ZGMMV is a very close relative of KGMMV and CFMMV (Fig. 2). ZGMMV, KGMMV, CFMMV, and CGMMV could be clustered in one subgroup in the coding regions analyses (Fig. 2A to D). ZGMMV was most similar to KGMMV and then to CFMMV, and was less similar to CGMMV. Separate analyses of the nucleotide sequences of the coding regions confirmed that ZGMMV grouped with KGMMV, CFMMV, and CGMMV (data not shown). Antignus et al. (3) divided the cucurbit-infecting tobamoviruses into two sub-subgroups; sub-subgroup I comprising the strains and isolates of CGMMV and sub-subgroup II comprising CFMMV and KGMMV. We conclude that ZGMMV is a new virus within the genus Tobamovirus and can be placed into the subgroup of viruses (CGMMV, CFMMV, and KGMMV) that infects cucurbits. An explanation for a such simple correlation between host plants and phylogenetic groupings is that most of the tobamoviruses have coevolved with their hosts. It seems likely that the long-term survival of most Tobamovirus species in nature depends on their adaptation to a particular family of plants $(13,21)$.

Production of cell-free infectious transcripts of ZGMMV. Full-length cDNA copies of ZGMMV were amplified by RT-PCR with the $5^{\prime}$-end upstream and $3^{\prime}$-end downstream primers (Fig. 1A). We obtained high quality full-length cDNA products of $6.5 \mathrm{~kb}$ by RT-PCR. Yields over $26.5 \mu \mathrm{g}$ of transcript from $0.1 \mu \mathrm{g}$ of viral RNA were obtained by this procedure. Total nucleic acids from ZGMMV-infected cucumber and zucchini squash leaves also gave significant amounts of the full-length RT-PCR product (approximately $10 \mu \mathrm{g}$ ) with the same primers and the same conditions (data not shown). The full-length cDNA molecules could be transcribed in vitro to produce transcript viral RNA yielding $12 \mu \mathrm{g}$ of RNA from $3 \mu \mathrm{g}$ of a PCR product (Fig. 1B). ZGMMV transcripts synthesized in the presence of cap analog were highly infectious on host plants. Ten (SphI-uncut) or three (SphI-cut) 3'-nonviral nucleotides originating from the 3'-end primer (Fig. 1A) did not prevent infection (Table 4). The majority of zucchini squash, cucumber, and $N$. benthamiana plants inoculated with capped transcripts from RT-PCR product developed mottle and mosaic symptoms typical of infection by ZGMMV (Table 4). The symptoms were indistinguishable from those generated by infections by ZGMMV virions or by sap inoculation of the virus-infected plants (data not shown). This cell-free system to produce infectious transcripts from uncloned cDNA is useful for the quick determination of the infectivity of transcripts from cDNAs representing viruses prior to their cloning into a vector. This procedure could have some practical applications, such as allowing researchers to avoid plasmid instability problems during normal cloning procedures; a situation we encountered with our construct in pUC18 in various $E$. coli strains. Similar result for in vivo transcription with $35 \mathrm{~S}$ promoter-anchored cell-free cloning was reported for Potato virus $Y(11)$. To our knowledge, this is the first example of a simple and quick cell-free system of plant RNA viruses for the assessment of infectious in vitro transcription.

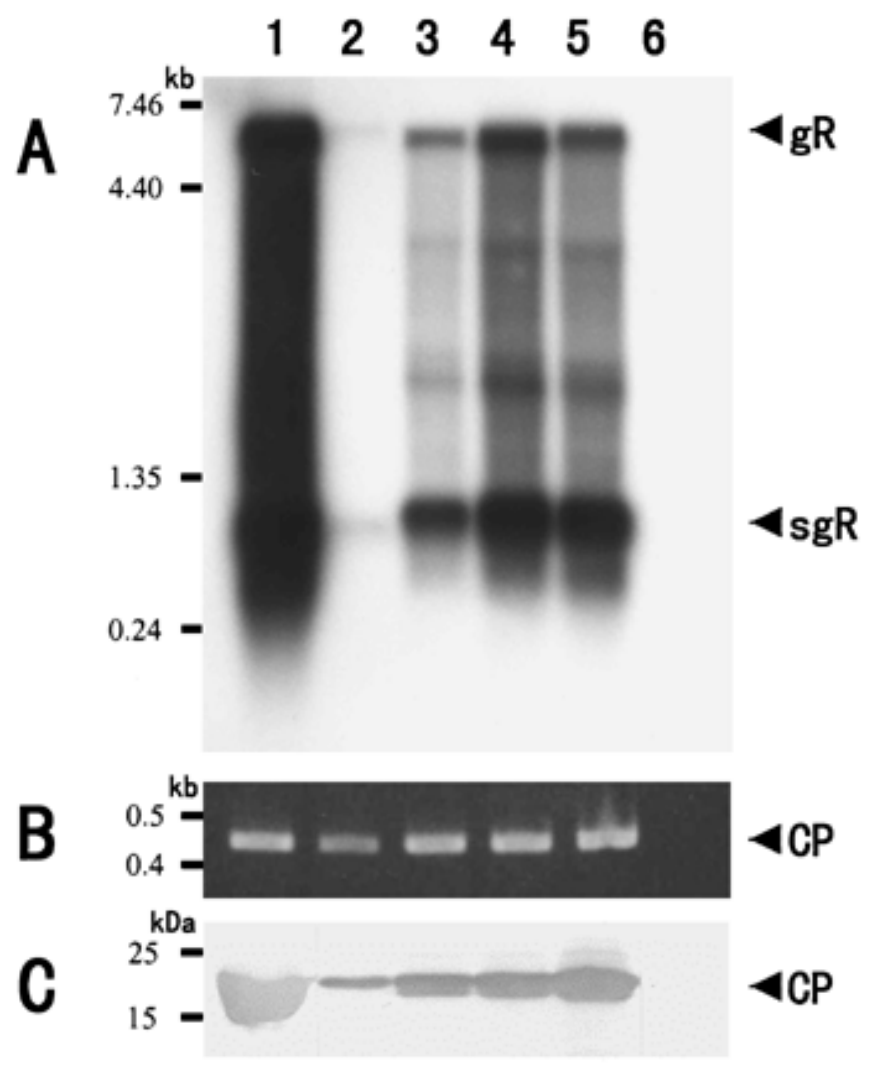

Fig. 3. Detection of virus-specific gene or coat protein from zucchini squash plants inoculated with in vitro transcripts from a full-length cDNA clone of Zucchini green mottle mosaic virus (ZGMMV). A, Northern blot analysis for viral RNA accumulation on in vitro transcript-inoculated plants. Blot was probed with transcript complementary to ZGMMV (+) strand sequence. B, Detection of the coat protein gene sequence of ZGMMV by reverse transcription and polymerase chain reaction. C, Western blot analysis of ZGMMV coat protein immuno-probed with ZGMMV coat protein antibody. Samples were prepared from zucchini squash leaves. A and B, Purified viral RNA (lane 1) and C, purified virion (lane 1), transcript-inoculated leaf (lane 2), the first upper leaf (lane 3), the second upper leaf (lane 4), wild-type ZGMMV-infected second upper leaf (lane 5), and healthy leaf as a negative control (lane 6). Abbreviations of $\mathrm{gR}, \mathrm{sgR}$, and $\mathrm{CP}$ in the right of photos represent genomic RNA, subgenomic RNA, and coat protein, respectively.

TABLE 4. Assay of infectivity of in vitro transcript RNAs of Zucchini green mottle mosaic virus (ZGMMV) transcribed from the reverse transcriptionpolymerase chain reaction (RT-PCR) product and from cloned cDNA on three host plants ${ }^{\mathrm{a}}$

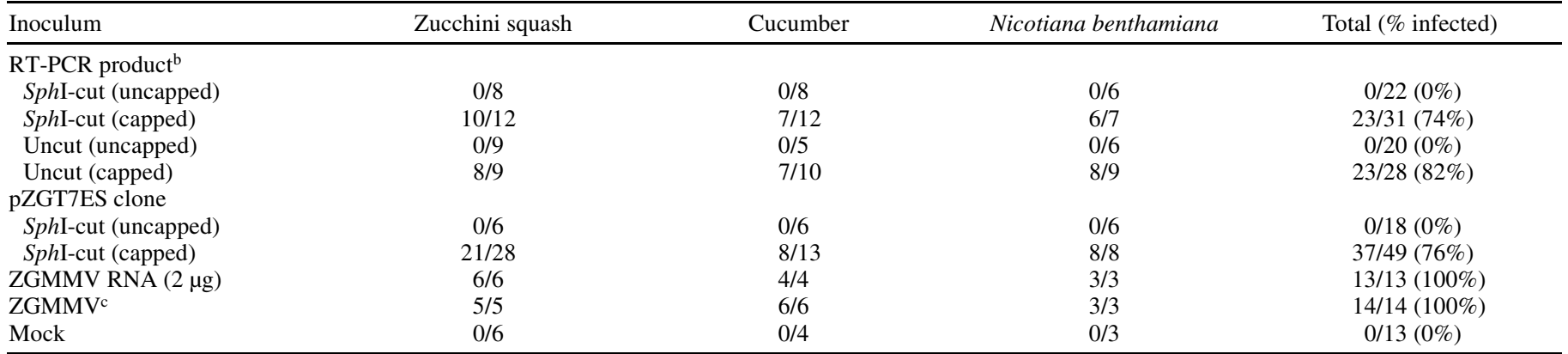

${ }^{a}$ Number of plants infected/number of plants inoculated.

${ }^{\mathrm{b}}$ Full-length RT-PCR product containing T7 RNA promoter sequence in the $5^{\prime}$ end used directly as template DNA for transcription reaction.

${ }^{c}$ Sap from zucchini squash plants infected with ZGMMV. 
In vitro transcript of ZGMMV from cloned cDNA is highly infectious. The full-length cDNA of ZGMMV, present in plasmid pZGT7ES, utilized pUC18 to allow the in vitro transcription of infectious viral RNA (Fig. 1B). The full-length cDNA clone was not stable; in some E. coli strains tested (JM109, HB101, and XL1Blue). However, the insert was stable in pGEMT-Easy (Promega) in all the E. coli strains (data not shown). The full-length cDNA clone was linearized with $S p h \mathrm{I}$ and transcribed with T7 RNA polymerase and the product was mechanically inoculated to three plants species. Capped ZGMMV transcripts were infectious in 21 of $28(75 \%), 8$ of $13(62 \%)$, and 8 of $8(100 \%)$ zucchini squash, cucumber, and $N$. benthamiana plants, respectively (Table 4). Uncapped transcripts were not infectious (Table 4). The presence of ZGMMV in inoculated and upper leaves of the plants was determined by RT-PCR with ZGMMV CP-specific primers or by northern and western blot analyses (Fig. 3). The number of infectious units inoculated for both transcript and wild-type virus were determined by local lesion assay on $D$. stramonium to verify that the quantity of infectious virus was the same between virus and transcript in each experiment (data not shown). The amounts of viral RNA and CP detected were at a similar level for plants inoculated with in vitro transcripts (Fig. 3, lane 4) and for control plants inoculated with wild-type ZGMMV (Fig. 3, lane 5). No significant difference of symptom expression and replication occurred when SphI enzyme was used to linearize the clone for run-off transcription, although this resulted in three extra nucleotides being added to the $3^{\prime}$ terminus of the RNA. The appearance of symptoms in the plants inoculated with the infectious transcript was delayed for 2 to 5 days compared with plants inoculated with native viral RNA. The first systemic symptom appeared on the second leaf above the inoculated leaf, with mottle symptoms appearing 8 to 10 days postinoculation (dpi) and green mottle mosaic symptoms appearing 10 to $12 \mathrm{dpi}$ on the upper leaves of zucchini squash (data not shown). This ZGMMV full-length cDNA clone is the first completely sequenced cucurbit-infecting tobamovirus clone from which highly infectious transcript was reported.

Virus from plants infected with transcript could be passaged to healthy plants yielding the same symptoms. Progeny virus derived from transcripts infected several host plants, with local lesions developing on $D$. stramonium at $6 \mathrm{dpi}$ and systemic symptoms appearing on the same plants at 7 to 10 dpi (data not shown). These symptoms and the timing of their appearance were identical to those induced by the native ZGMMV. Progeny virus derived from infectious in vitro transcripts was efficiently transmitted by sap inoculation on its host plants, and its physical and biochemical properties were the same with wild-type virus (data not shown). There was no difference between the progeny virus from transcripts and native ZGMMV when the progeny virus was passaged from zucchini squash to other host plants listed in Table 1 and assayed in replicate experiments (data not shown). Our results indicate that the in vitro transcript of ZGMMV is biologically active and yields symptoms indistinguishable from those of the native virus.

\section{ACKNOWLEDGMENTS}

This study was supported in part by Basic Research Grants (20002202-007-3) from the Korea Science \& Engineering Foundation. We thank R. S. Nelson, D. J. Lewandowski, P. Palukaitis, and C. Masuta for their critical reading of the manuscript and fruitful comments.

\section{LITERATURE CITED}

1. Aguilar, I., Sanchez, F., Martin, M. A., Martinez-Herrera, D., and Ponz, F. 1996. Nucleotide sequence of Chinese rape mosaic virus (oilseed rape mosaic virus), a crucifer tobamovirus infectious on Arabidopsis thaliana. Plant Mol. Biol. 30:191-197.

2. Alonso, E., Garcia-Luque, I., de la Cruz, A., Wicke, B., Avila-Rincon, M.
J., Serra, M. T., Castresana, C., and Diaz-Ruiz, J. R. 1991. Nucleotide sequence of the genomic RNA of pepper mild mottle virus, a resistancebreaking tobamovirus in pepper. J. Gen. Virol. 72:2875-2884.

3. Antignus, Y., Wang, Y., Pearlsman, M., Lachman, O., Lavi, N., and GalOn, A. 2001. Biological and molecular characterization of a new cucurbit-infecting tobamovirus. Phytopathology 91:565-571.

4. Bergh, S. T., Koziel, M. G., Huang, S. C., Thomas, R. A., Gilley, D. P, and Siegel, A. 1985. The nucleotide sequence of tobacco rattle virus RNA-2 (CAM strain). Nucleic Acids Res. 13:8507-8518.

5. Chapman, S. N. 1998. Tobamovirus isolation and RNA extraction. Pages 123-129 in: Plant Virology Protocols. G. D. Foster and S. C. Taylor, eds. Humana Press, New Jersey.

6. Chen, J., Watanabe, Y., Sako, N., Ohshima, K., and Okada, Y. 1996. Complete nucleotide sequence and synthesis of infectious in vitro transcripts from a full-length cDNA clone of a rakkyo strain of tobacco mosaic virus. Arch. Virol. 141:885-900.

7. Choi, G. S., Kim, J. H., Chung, B. N., Kim, H. R., and Choi, Y. M. 2001. Simultaneous detection of three tobamoviruses in cucurbits by rapid immunofilter paper assay. Plant Pathol. J. 17:106-109.

8. Clark, M. F., and Adams, A. N. 1977. Characterization of the microplate method of enzyme linked immunosorbent assay for detection of plant viruses. J. Gen. Virol. 34:475-483.

9. Dawson, W. O., Beck, D. L., Knorr, D. A., and Grantham, G. L. 1986. cDNA cloning of the complete genome of tobacco mosaic virus and production of infectious transcripts. Proc. Natl. Acad. Sci. USA 83:18321836.

10. Dorokhov, Y. L., Ivanov, P. A., Novikov, V. K., Agranovsky, A. A., Morozov, S. Y., Efimov, V. A., Casper, R., and Atabekov, J. G. 1994. Complete nucleotide sequence and genome organization of a tobamovirus infecting cruciferae plants. FEBS Lett. 350:5-8.

11. Fakhfakh, H., Vilaine, F., Makni, M., and Robaglia, C. 1996. Cell-free cloning and biolistic inoculation of an infectious cDNA of potato virus $\mathrm{Y}$ J. Gen. Virol. 77:519-523.

12. Francki, R. I. B., Hu, J., and Palukaitis, P. 1986. Taxonomy of cucurbitinfecting tobamoviruses as determined by serological and molecular hybridization analyses. Intervirology 26:156-163.

13. Gibbs, A. 1999. Evolution and origins of tobamoviruses. Phil. Trans. R. Soc. Lond. B. 354:593-602.

14. Gibbs, A. J. 1986. Tobamovirus classification. Pages 167-180 in: The Plant Viruses, Vol. 2. M. H. V. Van Regenmortel and H. Fraenkel-Conrat, eds. Plenum Press, New York.

15. Goelet, P., Lomonossoff, G. P., Butler, P. J., Akam, M. E., Gait, M. J., and Karn, J. 1982. Nucleotide sequence of tobacco mosaic virus RNA. Proc. Natl. Acad. Sci. USA 79:5818-5822.

16. Grdzelishvili, V. Z., Chapman, S. N., Dawson, W. O., and Lewandowski, D. J. 2000. Mapping of the tobacco mosaic virus movement protein and coat protein subgenomic RNA promoters in vivo. Virology 275:177-192.

17. Holt, C. A., and Beachy, R. N. 1991. In vivo complementation of infectious transcripts from mutant tobacco mosaic virus cDNAs in transgenic plants. Virology 181:109-117.

18. Ikeda, R., Watanabe, E., Watanabe, Y., and Okada, Y. 1993. Nucleotide sequence of tobamovirus $\mathrm{Ob}$ which can spread systemically in $\mathrm{N}$ gene tobacco. J. Gen. Virol. 74:1939-1944.

19. Ishikawa, M., Meshi, T., Motoyoshi, F., Takamatsu, N., and Okada, Y. 1986. In vitro mutagenesis of the putative replicase genes of tobacco mosaic virus. Nucleic Acids Res. 14:8291-8305.

20. Lartey, R. T., Voss, T. C., and Melcher, U. 1995. Completion of a cDNA sequence from a tobamovirus pathogenic to crucifers. Gene 166:331332.

21. Lartey, R. T., Voss, T. C., and Melcher, U. 1996. Tobamovirus evolution: Gene overlaps, recombination, and taxonomic implications. Mol. Biol. Evol. 13:1327-1338.

22. Lewandowski, D. J. 2000. Genus Tobamovirus. Pages 889-894 in: Virus Taxonomy. Seventh Report of the International Committee on Taxonomy of Viruses. M. H. V. Van Regenmortel, C. M. Fauquet, D. H. L. Bishop, E. B. Carstens M. K. Estes, S. M. Lemon, J. Maniloff, M. A. Mayo, D. J. McGeoch, C. R. Pringle, and R. B. Wickner, eds. Academic Press, San Diego.

23. Lewandowski, D. J., and Dawson, W. O. 2000. Functions of the 126- and 183-kDa proteins of tobacco mosaic virus. Virology 271:90-98.

24. Meshi, T., Ishikawa, M., Motoyoshi, F., Semba, K., and Okada, Y. 1986. In vitro transcription of infectious RNAs from full-length cDNAs of tobacco mosaic virus. Proc. Natl. Acad. Sci. USA 81:1966-1970.

25. Naidu, R. A., Miller, J. S., Mayo, M. A., Wesley, S. V., and Reddy, A. S. 2000. The nucleotide sequence of Indian peanut clump virus RNA 2: Sequence comparisons among pecluviruses. Arch. Virol. 145:1857-1866.

26. Nameth, S. T., Dodds, J. A., Paulus, A. O., and Laemmlen, F. F. 1986. Cucurbit viruses of California: An ever-changing problems. Plant Dis. 70:8-12.

27. Ohno, T., Aoyagi, M., Yamanashi, Y., Saito, H., Ikawa, S., Meshi, T., and 
Okada, Y. 1984. Nucleotide sequence of the tobacco mosaic virus (tomato strain) genome and comparison with the common strain genome. J. Biochem. 96:1915-1923.

28. Padgett, H. S., and Beachy, R. N. 1993. Analysis of a tobacco mosaic virus strain capable of overcoming $\mathrm{N}$ gene-mediated resistance. Plant Cell 5:577-586.

29. Ryu, K. H., Min, B. E., Choi, G. S., Choi, S. H., Kwon, S. B., Nola, G. M., Yoon, J. Y., Choi, Y. M., Jang, S. H., Lee, G. P., Cho, K. H., and Park, W. M. 2000. Zucchini green mottle mosaic virus is a new tobamovirus: Comparison of its coat protein gene with that of kyuri green mottle mosaic virus. Arch. Virol. 145:2325-2333.

30. Ryu, K. H., and Park, W. M. 1995. The complete nucleotide sequence and genome organization of odontoglossum ringspot tobamovirus RNA. Arch. Virol. 140:1577-1587.

31. Saitou, N., and Nei, M. 1987. The neighbor-joining method: A new method for reconstructing phylogenetic trees. Mol. Biol. Evol. 4:406425 .

32. Sambrook, J., Fritsch, E. F., and Maniatis, T. 1989. Molecular Cloning: A Laboratory Manual. 2nd ed. Cold Spring Harbor Laboratory, Cold Spring Harbor, NY.

33. Shimamoto, I., Sonoda, S., Vazquez, P., Minaka, N., and Nishiguchi, M. 1998. Nucleotide sequence analysis of the 3 '-terminal region of a wasabi strain of crucifer tobamovirus genomic RNA: Subgrouping of crucifer tobamoviruses. Arch. Virol. 143:1801-1813.

34. Shirako, Y., and Wilson, M. A. 1993. Complete nucleotide sequence and organization of the bipartite RNA genome of soil-borne wheat mosaic virus. Virology 195:16-32.
35. Silver, S., Quan, S., and Deom, C. M. 1996. Completion of the nucleotide sequence of sunn-hemp mosaic virus: A tobamovirus pathogenic to legumes. Virus Genes 13:83-85.

36. Solis, I., and Garcia-Arenal, F. 1990. The complete nucleotide sequence of the genomic RNA of the tobamovirus tobacco mild green mosaic virus. Virology 177:553-558.

37. Tan, S. H., Nishiguchi, M., Murata, M., and Motoyoshi, F. 2000. The genome structure of kyuri green mottle mosaic tobamovirus and its comparison with that of cucumber green mottle mosaic tobamovirus. Arch. Virol. 145:1067-1079.

38. Ugaki, M., Tomiyama, M., Kakutani, T., Hidaka, S., Kiguchi, T., Nagata, R., Sato, T., Motoyoshi, F., and Nishiguchi, M. 1991. The complete nucleotide sequence of cucumber green mottle mosaic virus (SH strain) genomic RNA. J. Gen. Virol. 72:1487-1495.

39. Weber, H., Haeckel, P., and Pfitzner, A. J. 1992. A cDNA clone of tomato mosaic virus is infectious in plants. J. Virol. 66:3909-3912.

40. Yamanaka, T., Komatani, H., Meshi, T., Naito, S., Ishikawa, M., and Ohno, T. 1998. Complete nucleotide sequence of the genomic RNA of tobacco mosaic virus strain $\mathrm{Cg}$. Virus Genes 16:173-176.

41. Yu, H. H., and Wong, S. M. 1998. A DNA clone encoding the full-length infectious genome of odontoglossum ringspot tobamovirus and mutagenesis of its coat protein gene. Arch. Virol. 143:163-171.

42. Zhang, Y., Lartey, R. T., Hartson, S. D., Voss, T. C., and Melcher, U. 1999. Limitations to tobacco mosaic virus infection of turnip. Arch. Virol. 144:957-971.

43. Zimmern, D. 1975. The $5^{\prime}$ end group of tobacco mosaic virus RNA is $\mathrm{m}^{7} \mathrm{G} 5^{\prime}$ ppp5'Gp. Nucleic Acids Res. 2:1189-1201. 